Ledezma, C. A. (2021). La iconología de la pintura de la Jerusalén Celeste Agustina en el Santuario de Chalma, México. Revista Herencia, Vol. 34 (1), enero-junio, 49-62.

\title{
LA ICONOLOGÍA DE LA PINTURA DE LA JERUSALÉN CELESTE AGUSTINA EN EL SANTUARIO DE CHALMA, MÉXICO
}

The iconology of the painting of the Jerusalem Celeste Agustina in the Shrine of Chalma, Mexico

\author{
Carlos Alfonso Ledesma Ibarra \\ Universidad Autónoma del Estado de México, México \\ cledesmai@yahoo.com.mx
}

Recibido: $24-09-2020$

Aprobado: 12-10-2020

\section{RESUMEN:}

Carlos Alfonso Ledesma Ibarra es Doctor en Historia del Arte por la Universidad Nacional Autónoma de México. Actualmente se desempeña como profesor e investigador de Tiempo Completo de la Universidad Autónoma del Estado de México. Sus principales líneas de investigación están alrededor del Arte Mexicano durante el siglo XIX y la época virreinal.

En el Santuario del Santo Señor de Chalma se venera una escultura de un Crucifijo proveniente desde el siglo XVI, y que de acuerdo con las crónicas agustinas fue uno de los elementos más importantes para lograr la evangelización de dicha región. La devoción alrededor del Cristo Crucificado de Chalma creció durante el siglo XVII lo que impulsó la construcción de un convento y un santuario.

El 6 de septiembre 1783, el rey Carlos III expidió una cédula que le confirió al recinto el título de "Real Convento y Santuario de Nuestro Señor Jesucristo y San Miguel de las cuevas de Chalma". Unos años más tarde durante la primera década del siglo XIX fue decorada su sacristía con cinco extraordinarios lienzos que, afortunadamente, se han conservado en su sitio original. Este escrito procura una interpretación iconográfica de estas imágenes, entre las que destaca la representación de una Jerusalén Celeste con San Agustín al centro de su composición.

Palabras clave: Santuario; Chalma; Iconografía; Pintura Virreinal; Jerusalén Celestial.

\section{ABSTRACT:}

In the Shrine of Santo Señor de Chalma is venerated an image of a Crucifix from the 16th century, and which according to the Augustinian chronicles was one of the most important elements in the evangelization of that region. The devotion around the Crucified Christ of Chalma grew during the 17th century, which prompted the construction of a convent and a shrine.

On September 6, 1783, King Carlos III, issued a certificate that gave the site the title of "Royal Convent and Shrine of Our Lord Jesus Christ and Saint Michael of the Caves from Chalma." A few years later during the first decade of the 19th century the sacristy was decorated with five extraordinaries canvases that, fortunately, have been preserved in their original place. This paper an iconographic interpretation of these images, among which the representation of a Celestial Jerusalem with Saint Augustine at the center of its composition.

Keywords: Shrine; Chalma; Iconography; Painting Viceregal; Celestial Jerusalem.

\section{Introducción}

Chalma es una pequeña localidad enclavada en una accidentada superficie, cien kilómetros al sur de la Ciudad de México. Está ubicada entre dos poblaciones que eran importantes desde la época posclásica del periodo prehispánico y que mantuvieron parte de su preeminencia aún durante el periodo virreinal: Malinalco y Ocuilan. La relación de Chalma con Malinalco se remonta a su fundación. Este pequeño valle está enmarcado entre 
sinuosas elevaciones, su clima es benevolente, las lluvias copiosas en verano, la vegetación exuberante, la vida animal variada y posee abundantes manantiales que originan ríos y arroyos. El prodigioso paisaje del lugar es la explicación de su temprana ocupación humana.

Esta región fue conquistada por las tropas hispano - indígenas bajo el mando de Andrés de Tapia en 1521 durante el sitio de México - Tenochtitlan. Para su evangelización recibió la visita de los Ermitaños de San Agustín, los cuales arribaron a la Nueva España en 1533. En 1543, los agustinos fundaron un importante convento en la cercana población de Malinalco, ubicada diez kilómetros al noroeste (Ledesma, 2008, p. 43).

Se cuenta que cuatro años antes, en 1539, en una cueva de Chalma, sucedió la aparición milagrosa de una escultura de Cristo Crucificado donde, según la tradición, anteriormente, se veneraba a Oxtotéotl, una supuesta advocación de Tezcatlipoca. Dos frailes agustinos que entonces predicaban en esa región fueron encargados de la destrucción de la antigua imagen. Nicolás de Perea y Sebastián de Tolentino dijeron que al entrar en la cueva encontraron al ídolo despedazado y en su lugar el crucifijo. Las crónicas de los agustinos aseguran que fueron los propios ángeles quienes se encargaron de destruir la escultura del antiguo dios y dejar en su lugar un Santo Cristo (Grijalva, 1924, p. VII).

De esta manera, era responsabilidad angélica la expulsión del antiguo culto para ser sustituido por la imagen de un Cristo Crucificado de hechura milagrosa. En los primeros años posteriores a la aparición milagrosa, seguramente, se improvisó en el lugar un adoratorio que diera albergue a la imagen, que permaneció en una cueva. Algunos frailes agustinos llegaban eventualmente a la población para atender espiritualmente a los habitantes y a los peregrinos, quienes ya llegaban desde entonces a visitar la milagrosa imagen. En otras palabras, en este lugar convergieron: el carácter sagrado que tenían las cavernas para el pensamiento religioso de los naturales y la convicción agustiniana de poseer santuarios aislados que permitieran el retiro completo y la contemplación de sus religiosos y la tradición sagrada de esta región (Rubial, 2008, p. 89). 
De acuerdo con las crónicas agustinas, de no ser por la visita esporádica de dichos frailes, la cueva de Chalma y el crucifijo milagroso hubieran permanecido en la más completa soledad. Sin embargo, en 1623, un pecador arrepentido, Bartolomé de Jesús María, hizo votos de residir hasta su muerte en esas cuevas. A este personaje, por su dedicación y predicación, se le atribuye la responsabilidad de la fundación de un primer pequeño convento de Chalma y el aumento progresivo e irrefrenable del culto de la imagen (Grijalva, 1924, p. VII).

Fray Bartolomé de Jesús María fue ayudado por su discípulo, fray Juan de San Joseph, con la autorización de sus superiores, los que recibieron abundantes limosnas y donaciones de los fieles que eran destinadas a la construcción de pequeñas estancias para hospedar a los peregrinos, quienes llegaban cada vez con mayor frecuencia para visitar la imagen milagrosa y al propio predicador que alcanzó la fama de obrar milagros. Asimismo, se inició la edificación de un pequeño convento de clausura con techos de tejamanil, para los frailes que quisieran vivir en completo aislamiento. Este personaje falleció en 1658. Sus restos permanecieron en el lugar y fueron un nuevo motivo para la llegada de más devotos (Rubial, 2010, p. 224).

Fray Antonio Quesada fue elegido provincial de los Ermitaños de San Agustín en 1680; anteriormente había sido encargado de visitar los conventos de la provincia del Santísimo Nombre de Jesús y, sabedor de la importancia que había cobrado el lugar, comisionó a fray Diego Velázquez de la Cadena para que estableciera un convento en Chalma. Éste, previamente, había estado en los conventos de Malinalco y Ocuilan y conocía la región y la notoriedad de las cuevas de Chalma. Las construcciones alrededor de este sitio, pequeñas estancias para peregrinos y algunas capillas, fueron el antecedente para establecer aquí un convento y un Santuario para la imagen.

La primera construcción del templo y su convento concluyeron en 1683. El primero fue consagrado a la Virgen de Guadalupe, el 5 de marzo de ese mismo año, y fue entonces cuando el crucifijo se trasladó, solemnemente y en medio de gran fiesta, de la cueva de su aparición al lugar principal del presbiterio del Santuario (Sardo, 1810, p. 113). El primer edificio del Santuario tuvo varias modificaciones, paulatinamente. La distribución original 
se vio tan alterada que se planteó la necesidad de un nuevo edificio apenas unos años más tarde. La primera etapa constructiva documentada comenzó en 1721 y terminó en abril de 1729. Sobre este aspecto, "La Gaceta de México", del 23 de enero de 1730, registra información valiosa, pues menciona que el Provincial agustino de la Nueva España realizó la bendición del retablo mayor que había costado la extraordinaria suma de poco más de diez mil pesos. Por su elevado costo, es muy probable que dicho mueble incluyera en su construcción, decoración y ensamblaje varias partes en plata.

La información anotada en "La Gaceta de México" muestra los importantes recursos con los que contaba este Santuario y la significativa cantidad de obras de construcción, remodelación y arreglo realizados durante la primera mitad del siglo XVIII. Este embellecimiento interior del edificio continuó por el resto de esta centuria e inicios de la siguiente, como testimonia fray Joaquín de Sardo, quien no dudaba en compararlo con los mayores santuarios de Europa (Sardo, 1810, p. 114). Uno de los beneficios más importantes obtenidos por el Santuario de Chalma sucedió el 6 de septiembre 1783, cuando el rey Carlos III expidió la cédula que le confirió al recinto el título de "Real Convento y Santuario de Nuestro Señor Jesucristo y San Miguel de las cuevas de Chalma". Con dicho título, el convento, el santuario y la cueva fueron dedicados a San Miguel Arcángel, quien también fue el encargado de desterrar las tinieblas de la idolatría del Nuevo Mundo (Sardo, 1810, p. 120).

\section{La Sacristía}

La sacristía es el cuarto donde se resguardan los utensilios sagrados, ornamentos, vasos sagrados, casullas, sotanas y otros tesoros. En este lugar también se revisten los religiosos antes de las ceremonias eclesiásticas. En el Santuario dicho espacio se construyó y decoró en 1809, durante el priorato de fray Joaquín Sardo, de acuerdo con una inscripción de uno de sus muros. Sin embargo, lamentablemente, ésta no proporciona dato alguno sobre el pintor o pintores encargados de los enormes lienzos que se encuentran en este lugar y que, evidentemente, no tienen la misma autoría [Figura 1]. 
En el testero de dicho espacio se encuentra un lienzo monumental que ocupa la totalidad del muro y representa a la Jerusalén Triunfante, alusivo a la orden de los Ermitaños de San Agustín: “y en el centro deja verse figurado en un sol N.P.S. Agustín, como luz de la iglesia se halla iluminando la ciudad santa" (Sardo, 1810, p. 134). Según Antonio Rubial este cuadro fue pintado en 1778 pero no se conoce el nombre de su autor o autores (Rubial, 1998, p. 18).

La referencia literaria de esta imagen se encuentra en el libro de las Revelaciones o el Apocalipsis escrito por San Juan. La Jerusalén Celestial es descrita por el evangelista en el capítulo 21: "Y vi la ciudad santa, la nueva Jerusalén, que bajaba del cielo, de junto a Dios, engalanada como una novia adornada para su esposo" (versículo 2). Esta sería la ciudad de Dios, donde Él reina y gobierna. No hay lugar en ésta para los incrédulos, los impuros, los hechiceros y los idólatras. Palabras que retomaría San Agustín para su reflexión y el artífice de Chalma para su recreación.

En la pintura se pueden distinguir, al flanquear la puerta principal de la ciudad Sagrada, a Santa Elena y un ángel. La santa aparece con la cruz de Cristo, pues fue ella quien la localizó en Jerusalén, a principios del siglo IV, y después fue promotora de su culto. Más aún, como madre del emperador romano Constantino, mandó construir tres templos en Tierra Santa: en Belén, en el Monte de los Olivos y en el Calvario. En la pintura, el ángel y Santa Elena parecieran invitarnos a traspasar el umbral donde se encuentran y nos señalan la entrada a un pasillo lleno de flores multicolores.

En el centro de la composición se encuentra un enorme y magnífico San Agustín de abundante barba, vestido de hábito negro, que lleva un gran libro en su mano izquierda y una pluma en la mano derecha que enfatizan su labor como doctor de la Iglesia Católica. Está rodeado por el sol y se eleva sobre la Jerusalén Sagrada. En la parte media de la pintura varios angelitos y querubines acuden al santo fundador con las insignias pontificales por su condición de obispo de Hipona: un par de ellos se aproxima con la mitra, otro con el báculo, uno más con el cíngulo y otro abre un libro. 
En el centro de la Jerusalén Celestial se encuentra la madre de San Agustín, Santa Mónica, quien viste de negro y lleva un pañuelo entre las manos, atributo de su sufrimiento anterior a la conversión de éste. Ella, de menor tamaño, eleva la mirada hacia su hijo. La madre del santo fundador y la principal impulsora de su conversión, se encuentra rodeada por los muros dorados con incrustaciones de piedras preciosas de la ciudad, la cual tiene un aspecto más cercano a hortus conclusus, ya que sus divisiones geométricas parecen remitirnos a un jardín francés como los difundidos en los grabados de los hermanos Klauber (Rubial, 1998, p. 19).

Nueve santos se encuentran sobre las murallas y visten de negro para indicar su pertenencia a las congregaciones femeninas y masculinas de los agustinos. De acuerdo con Antonio Rubial García, éstos han suplantado a los doce ángeles que debieran ubicarse aquí. Otro par de personajes está a sus costados y son obispos, pues en su indumentaria se distinguen la casulla, el báculo y la mitra. Uno de ellos es san Alipio, compañero y amigo de san Agustín (s. IV - V). Era el obispo de Tagaste, ciudad ubicada en el norte de África en la actual Argelia. De acuerdo con la tradición este santo acompañó al obispo de Hipona en su conversión al cristianismo. (Schenone, 1992, p. 125). El otro obispo es San Posidio, quien presidió la diócesis de Calama, ciudad de Numidia, también situada en el septentrión africano. Además, era compañero cercano de san Agustín y le acompañó en diversas acciones eclesiásticas. Estuvo presente en la muerte del obispo de Hipona.

Para identificar a los santos representados en los muros de la ciudad sagrada examinamos algunos de sus atributos que posteriormente se buscaron en las obras de Réau y Schenone.

Entre los representados se identificaron los siguientes: la primera del lado izquierdo, sería santa Clara de la Cruz Montefalco, quien antes de ser agustina perteneció a las Terciarias Franciscanas. Su atributo característico es un corazón sellado con los instrumentos de la Pasión, pues cuando su muerte estaba cercana y le hicieron la señal de la cruz en la frente, ella dijo tener ese mismo símbolo en su corazón. Después de morir, sus hermanas prepararon su cuerpo y le retiraron el corazón que guardaron en una caja como reliquia. Al día siguiente, después de su misa funeral, las monjas procedieron a colocar el corazón en 
un relicario y éste, milagrosamente, tenía grabados a Cristo en la cruz y otros símbolos pasionarios. Esta monja se distinguió por sus arrebatos místicos y su promoción por el culto a la Santa Cruz, labor encomendada por Jesucristo en una aparición. Murió en 1308 en Montefalco.

También podría estar, entre las santas representadas, santa Rita de Casia (1381 - 1457), quien ingresó con las monjas agustinas después de enviudar. Su atributo más característico es la herida en la frente por una espina de la corona de Jesús. Un estigma que le acompañaría por toda su vida. También suele representársele con rosas o una cruz entre sus brazos como aparece debajo del santo fundador. Es probable que la santa que lleva el libro haga alusión a Santa María Magdalena de Pazzi (1566 - 1607), quien fue una monja carmelita, según relata Schenone, en uno de los episodios milagrosos de su vida presenció la "Aparición de San Agustín":

\footnotetext{
Estaba la santa meditando un pasaje del Evangelio de San Juan cuando se le apareció San Agustín y le escribió en el corazón: Verbum Caro Factum Est (la palabra se hizo carne): la primera palabra en letras de oro, porque dicho metal precioso expresa mejor la divinidad de Cristo, mientras que las restantes estaban escritas con sangre simbolizando su santa Humanidad. (1992, Tomo 2, p. 576).
}

Si bien se le reconoce, principalmente, por sus arrebatos místicos, también se le representa con el atributo del libro debido a las diversas obras de que escribió.

Por otro lado, se encuentran los varones ubicados sobre el muro. El primero de la izquierda podría ser Santo Tomás de Villanueva (1486 - 1555). Este agustino era conocido como “el limosnero", pues usualmente es representado con vestiduras episcopales y una bolsa, aunque en este caso sólo lleva el báculo. Fue nombrado obispo de Valencia en 1544, también era consejero de Carlos $\mathrm{V}$ y fue un incansable promotor de la conversión de los moriscos. La mayoría de las pinturas que llegaron a nosotros de él proceden de finales del siglo XVII. También parece estar entre los representados debajo del santo fundador, el afamado San Nicolás de Tolentino (1245 - 1305), cuyo principal atributo es la estrella en el pecho, aunque también suele representársele con un crucifijo y la azucena. Llevó una vida 
ascética, de renuncia a lo material y dedicada a la oración. Fue el primer miembro de la orden de los agustinos canonizado en 1446.

También parece estar entre los pintados, el abad San Esteban (714 - 764), quien regularmente se representa con un icono de la Virgen María por la defensa que hizo del culto a los íconos y sería el último a la derecha. Este monje bizantino era reconocido por su disciplina, piedad, ascetismo y formación teológica que le llevó a defender el culto a las imágenes frente a los iconoclastas, entre ellos el emperador Corpónimo, quien finalmente lo encarceló y condenó a muerte. Es necesario reconocer que algunos de los atributos de estos personajes no son claros por el estado de conservación de la pintura.

Por otra parte, debe agregarse que este tipo de representaciones de San Agustín sobre la Jerusalén Celestial no eran extrañas, pues el santo fundador había expuesto en su obra la existencia de esa "Ciudad de Dios" superior a las ciudades del mundo. En su obra homónima, en el libro XX, capítulo IX, destinado a interpretar el Juicio Final, el obispo de Hipona afirmaba que en esa ciudad reinaría Cristo, sentado a la derecha de Dios Padre, en compañía de los mártires y los justos y con la ausencia de cualquier indicio del mal, pues éste no tendría lugar en dicha ciudad. Al parecer fue esta consideración una de las ideas centrales para la composición de la obra (Agustín, 1992, pp. 507 - 508).

A los costados del obispo de Hipona se localizan otros cuatro santos entre los que distinguimos por sus atributos a los siguientes: San Andrés con la cruz en forma de aspa (en ésta fue martirizado hasta su muerte), San Pedro con las llaves otorgadas por el propio Jesucristo, San Pablo con su espada y Santiago con su bordón de peregrino. Más arriba en la composición se localizan los otros apóstoles: San Mateo, el evangelista, quien aparece con un libro abierto sobre sus piernas, San Felipe que parece distinguirse por su bastón terminado en cruz latina y San Simón con una sierra por el martirio al que fue sometido en Perusia (Schenone, 1992, pp. 724-25).

En este sentido, el resto de los personajes pintados debieran identificarse como los apóstoles. Quedarían entonces por señalar con precisión a San Bartolomé, Santo Tomás, 
Santiago (el menor o hijo de Alfeo) y Tadeo (algunos le llaman Judas Tadeo). Cabe mencionarse que, a pesar de las condiciones actuales del lienzo, se alcanzan a distinguir los cuatro restantes. Así quedan distribuidos en el lienzo tres a la izquierda y cuatro a la derecha, en la parte superior y cuatro flanqueando a San Agustín; éstos, sumados a San Juan, que está en la parte inferior, sumarían los doce discípulos.

En la esquina inferior derecha del lienzo se encuentra San Juan Evangelista, quien se halla absorto y está acompañado por un ángel, el cual mira al espectador y apunta con una vara de medir hacia dónde debemos dirigir nuestra mirada, a la Ciudad Sagrada:

\footnotetext{
Me llevó en espíritu a un monte grande y alto y me mostró la ciudad santa, Jerusalén, que descendía del cielo de parte de Dios. Su brillo era semejante a la piedra más preciosa [...]. Tenía un muro grande y alto y doce puertas y sobre ellas doce ángeles y nombres escritos, que son los nombres de las doce tribus de los hijos de Israel [...]. El muro de la ciudad tenía doce hiladas y sobre ellas los nombres de los doce apóstoles del Cordero [...]. La ciudad estaba asentada sobre una base cuadrangular y su longitud era tanta como su anchura [...]. Pero templo no vi en ella pues el señor Dios con el Cordero era su templo [...] y su lumbrera era el cordero. (Apocalipsis, 21, $10-21$ )
}

El artífice de la pintura de Chalma se ha preocupado por representar con fidelidad dichos elementos. El apóstol, por su parte, se pintó con un libro abierto y un águila a sus pies. El libro como atributo, “...en manos de los Evangelistas y Apóstoles representa el Nuevo Testamento". El libro abierto en las manos de un fundador de una Orden es símbolo de la regla de ésta, tal como sucede en este lienzo. Así, fue frecuente que San Agustín haya sido representado con un libro y una pluma, atributos usualmente utilizados para los cuatro Evangelistas (Ferguson, 1961, p. 171).

En resumen, a pesar de lo deteriorado del lienzo, en la parte superior se distinguen los doce apóstoles, quienes acompañan a un Cristo en Majestad Salvator Mundi, que con la mano derecha imparte la bendición y con la izquierda sostiene el orbe, mientras se encuentra presidiendo la Jerusalén celeste. En los costados de la ventana abocinada, se localizan la Virgen María y San José, frente a ésta. Debajo de esta pareja están Santa Ana y San Joaquín frente a ella. En otras palabras, en esta parte superior de la composición se representan a los llamados cinco señores por su importancia. 


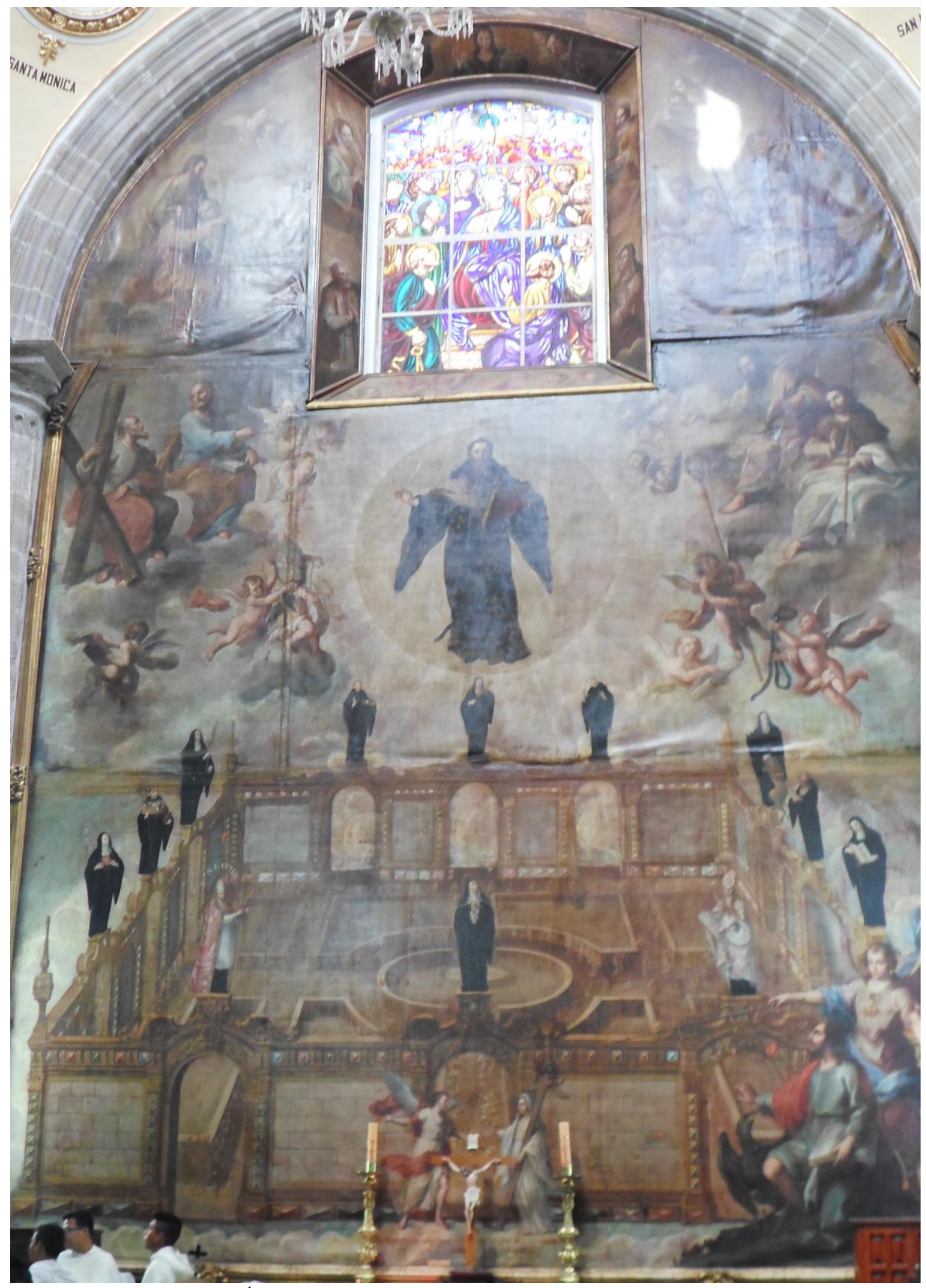

Figura 1. La Jerusalén Celeste; Óleo sobre lienzo; Autor desconocido; Foto: Carlos Ledesma. 


\section{Conclusiones}

El Santuario de Chalma fue fundado en un lugar considerado como sagrado; por ello no es extraño que haya acontecido el milagro de la aparición del Cristo en 1539. Con el paso del tiempo fue convirtiéndose en uno de los lugares de peregrinaje con mayor afluencia en el centro de la Nueva España. En el siglo XVII fue fray Bartolomé de Jesús María uno de los principales predicadores y recolectores de limosnas y donaciones en favor de la imagen del Crucifijo y promotor de la construcción de un Santuario. De esta manera las cuevas que originalmente sirvieron como recinto a algunas imágenes, frailes anacoretas y peregrinos, cedieron su sitio al Santuario construido al pie de la cañada y en la ribera del río que la atraviesa.

Las cuatro principales pinturas de la sacristía resaltan la temática sobre la expulsión del mal y la idolatría por parte del milagro del crucifijo aparecido. El extraordinario lienzo de la Jerusalén celestial, presidido por San Agustín de Hipona y los agustinos, es un ejemplo del discurso victorioso de la orden de los Ermitaños de San Agustín a finales de la época virreinal, pues sus santos se encuentran protagonizando el Triunfo de la Iglesia Católica en el fin de los tiempos. Los seguidores de San Agustín ocupan el lugar más cercano a Dios en la Jerusalén terrestre. Más aún, éstos se hacen acompañar por los doce primeros apóstoles, los fundadores de la Iglesia, los iniciadores de la cristianización; es decir, los primeros evangelizadores del orbe. Todos bajo la tutela de la familia del propio Jesucristo, quien preside la composición mientras lleva en sus manos el orbe e imparte la bendición.

Esta pintura celebra el triunfo de la orden de los Ermitaños de San Agustín como los principales en el cielo; el lugar preeminente de su fundador en la composición y los santos agustinos en las esquinas de la Jerusalén sagrada y al interior de ésta, así lo atestiguan (Rubial, 1998, p. 19). En un sentido similar, el Santuario de Chalma era esa prefiguración del triunfo final de la Iglesia militante y los justos sobre los pecadores y los idólatras.

También es conveniente señalar el protagonismo de Santa Elena y Santa Mónica en esta composición, pues ambas fueron evangelizadoras activas de sus propios hijos. De esta 
manera el Santuario también se ostentaba como piedra angular del inicio de la Evangelización y la expulsión del demonio de estas tierras. La Orden de los Ermitaños de San Agustín aparecía como su principal instrumento, según las crónicas y las pinturas localizadas en este lugar, las cuales daban su testimonio. La pintura mostraba ese aspecto narrativo que ahora permitía mirar lo que anteriormente solo se leía en las crónicas.

Más aún, las cinco pinturas que se ubican en la sacristía de Chalma pueden interpretarse como una narración en que se desarrolla la historia sagrada del lugar. Primeramente, se representa como un lugar de culto pagano, donde dominaba el demonio. Después, se reproduce la aparición de la imagen milagrosa: el paisaje, la fauna, la flora y los devotos se transforman en algo benigno. Un tercer momento puede ubicarse con el traslado del crucifijo al magnífico Santuario. Finalmente, somos testigos del triunfo de la fe católica, al final de los tiempos, donde la orden de los agustinos reina sobre la Jerusalén Celestial.

La pintura de San Miguel arrojando al demonio puede interpretarse, primeramente, como ese triunfo de la evangelización cristiana sobre los antiguos cultos, pues en el pensamiento de la época había sido el propio demonio el encargado de engañarlos con ese falso culto, más aún, en la propia obra de san Agustín, se localiza la siguiente afirmación: “[...] para que no engañe a las gentes [...] a las cuales tenía engañadas antes que hubiese Iglesia" (Agustín: 1992, 504). Pero al mismo tiempo, esta imagen representa la expulsión del Demonio de la Tierra: "Y le echó, dice, en el abismo, es a saber, lanzó al demonio en el abismo" (Agustín, 1992, p. 503). El destierro del mal era indispensable para que se produjera el reinado del bien. De esta manera, los enormes lienzos se vuelven episodios que culminan con la pintura del testero de la sacristía. La pintura provee los elementos en la visualización de lo que antes sólo habían escuchado.

Por otro lado, la composición del enorme lienzo significó un reto para el artista que debió de agrupar la visión apocalíptica, con los santos agustinos, los doce apóstoles y la familia de Jesús. Todo ello alrededor de una excelente pintura de San Agustín que se convierte en el vínculo imprescindible entre lo terrenal y lo celestial. La extraordinaria ejecución del artífice evidencia su experiencia y oficio al saber distribuir con equilibrio y simetría los personajes 
de la pintura, al mismo tiempo que todos guardan una cuidadosa relación jerárquica alrededor de la Santísima Trinidad y los santos.

La pintura fue protagonista en la construcción de un discurso que proclamaba el triunfo de la fe católica en la Nueva España, que no sólo era ahora una de sus más novedosas adquisiciones, sino que se había transformado en una tierra fértil en vocaciones, milagros, apariciones y santuarios. La predestinación había marcado el destino del Nuevo Mundo como una tierra santa, un centro renovado de la cristiandad, que se equiparaba con Jerusalén y, por supuesto, el sitio desde el que se podría vislumbrar el triunfo del catolicismo y el arribo de la Jerusalén Celeste en el fin de los tiempos.

\section{Bibliografía}

Agustín de Hipona. 1992. La Ciudad de Dios [Introducción: Francisco Montes de Oca], México: Porrúa.

Camacho Quiroz, R. 2018. "Vamos a ver cómo pasó... Crónica de la aparición del Cristo de Chalma", en Pensamiento Novohispano, IESU - Universidad Autónoma del Estado de México, 19, Toluca, México, septiembre, $125-138$.

Fernández, M. 2001. "La Jerusalén celeste. Imagen barroca de la ciudad novohispana" en Actas III. Congreso Internacional del barroco americano: Territorio, Espacio y Sociedad, Sevilla: Universidad Pablo de Olavide.

Grijalva, J. 1924. Crónica de la Orden de Nuestro Padre San Agustín, en las Provincias de Nueva España, en cuatro edades desde el año de 1533 hasta el de 1592 [Introducción y apéndices de Nicolás León] México: Imprenta Victoria.

Ledesma Ibarra, C. 2017. El inicio de la arquitectura neoclásica en el centro-sur del Estado de México. Los casos de Ocoyoacac, Lerma, Tenango del Valle, "Gualupita", Tenancingo y Chalma, Universidad Autónoma del Estado de México, Toluca, Estado de México.

Ledesma Ibarra, C. 2008. Las capillas de barrio en Malinalco, Universidad Autónoma del Estado de México, Toluca, Estado de México.

Obregón, G. 1953. "El Real Convento y Santuario de San Miguel de Chalma" en Estudios históricos americanos, El Colegio de México, México.

Réau, L. 2002. Iconografía del arte cristiano. Iconografía de los Santos. T.2. Vols. 1, 2. T.2. Vols. 3, 4, 5. España: Editorial Serbal. 
Rubial García, A. 1998. "Civitas Dei et novus orbis. La Jerusalén Celeste en la pintura de Nueva España", en Anales del Instituto de Investigaciones Estéticas, UNAM - IIE, 72, México, $5-37$.

Rubial García, A. 2010. El paraíso de los elegidos. Una lectura de la historia cultural de la Nueva España (1521 - 1804). México: FCE - UNAM.

Rubial García, A. 2008. "Hortus Eremitarum", en Anales del Instituto de Investigaciones Estéticas, UNAM-IIE, 92, México, 85 - 105.

Sahagún de Arévalo, J. 1949. Gacetas de México, v. II, Secretaría de Educación Pública, México.

Sardo, J. 1810. Relación histórica y moral de la portentosa imagen de N. Sr. Jesucristo crucificado aparecida en Chalma. México: Impresa en Casa Arizpe.

Schenone, H. 1992. Iconografía del Arte Colonial. Los Santos, 2 vols. Argentina: Ed. Fundación Tarea.

Sicardo, J. 1683. Interrogatorio de la vida y virtudes del venerable hermano Fr. Bartholomé de Jesús María. México: Impreso por Juan Ribera.

Victoria, J. 1992. Regionalización en el arte. Teoría y práctica, Gobierno del Estado de Sinaloa - UNAM - IIE, México. 
Revista Herencia, Vol. 34 (1), enero-junio, 2021.

ISSN IMPRESO: 1659-0066 ISSN ELECTRÓNICO: 2215-6356 